\title{
A Brief Overview of the Life and Work of Lyon Henry Appleby, M.D. (1895-1970).
}

\author{
Jon Harrison \\ Thomas Jefferson University \\ Michael J. Pucci \\ Thomas Jefferson University \\ Scott W. Cowan \\ Thomas Jefferson University \\ Charles Yeo \\ Thomas Jefferson University
}

Follow this and additional works at: https://jdc.jefferson.edu/gibbonsocietyprofiles

Part of the History of Science, Technology, and Medicine Commons, and the Surgery Commons Let us know how access to this document benefits you

\section{Recommended Citation}

Harrison, Jon; Pucci, Michael J.; Cowan, Scott W.; and Yeo, Charles, "A Brief Overview of the Life and Work of Lyon Henry Appleby, M.D. (1895-1970)." (2016). Department of Surgery Gibbon Society Historical Profiles. Paper 47.

https://jdc.jefferson.edu/gibbonsocietyprofiles/47

This Article is brought to you for free and open access by the Jefferson Digital Commons. The Jefferson Digital Commons is a service of Thomas Jefferson University's Center for Teaching and Learning (CTL). The Commons is a showcase for Jefferson books and journals, peer-reviewed scholarly publications, unique historical collections from the University archives, and teaching tools. The Jefferson Digital Commons allows researchers and interested readers anywhere in the world to learn about and keep up to date with Jefferson scholarship. This article has been accepted for inclusion in Department of Surgery Gibbon Society Historical Profiles by an authorized administrator of the Jefferson Digital Commons. For more information, please contact: JeffersonDigitalCommons@jefferson.edu. 


\title{
A Brief Overview of the Life and Work of Lyon Henry Appleby, M.D. (1895-1970)
}

JON HARRISON, B.S., MICHAEL J. PUCCI, M.D., SCOTT W. COWAN, M.D., CHARLES J. YEO, M.D.

\author{
From the Department of Surgery, Sidney Kimmel Medical College, Thomas Jefferson University, \\ Philadelphia, Pennsylvania
}

\begin{abstract}
The life and work of Dr. Lyon Henry Appleby, M.D., portrays the essence of a devoted clinician committed to scholarly excellence. Born in Deseronto, Ontario, in 1895 and passing in 1970, Dr. Appleby influenced all areas of general surgery, most notably popularizing a procedure that bears his name today. After a tour in World War I, he quickly proved himself to be a dedicated clinician with roots in academia, which translated into excellence within the Department of Surgery at St. Paul's Hospital in Vancouver, Canada. He served in various leadership roles including Chair of the Department of Surgery, President of the International College of Surgeons, and Fellow of the Royal College of Physicians and Surgeons. The Appleby procedure, or en bloc removal of the celiac axis, at the time of gastrectomy, is the technical focus of this paper, although reference is made to Appleby's extensive contributions to historical medicine.
\end{abstract}

$\mathrm{T}$ HROUGHOUT HIS COUNTLESS clinical and scholarly pursuits, Lyon Henry Appleby, MD (Fig. 1) established a pre-eminent legacy that continues to affect the lives of patients and their families today. Born in 1895 in Deseronto, Ontario, Canada, Dr. Appleby is best known for the eponymous procedure of en bloc removal of the celiac axis during oncologic procedures of the upper gastrointestinal tract. ${ }^{1,2}$ Originally described for gastric carcinoma, the technique has now been used for previously unresectable, locally advanced pancreatic tumors as well. His contributions to other aspects of gastrointestinal surgery and surgical history are numerous, with his charisma evident in all endeavors he pursued.

Appleby's early life is poorly documented. His brilliance, however, was revealed soon after he enrolled at Queen's University in Ontario in 1912. During this time, World War I interrupted his medical training as he bravely served for two years as a member of the No. 7 Hospital Company based in England, Egypt, and France. ${ }^{16}$ Appleby was part of a sevenmember collective of premedical students that "served with the highest character," 3 and were chosen for such reason. Embarking from Montreal on May 16, 1915, the outfit arrived in St. Martin's Plain, United Kingdom, after a lengthy seaward voyage. ${ }^{16}$ In Britain, the facility quickly grew from a 200 to 600 bed, permanent

Address correspondence and reprint requests to Scott W. Cowan, M.D., Department of Surgery, Sidney Kimmel Medical College, Thomas Jefferson University, 1025 Walnut Street, Suite 607, Philadelphia, PA 19107. E-mail: scott.cowan@jefferson.edu. hospital, a clear reflection of the growing health burden of war. By August, however, the No. 7 was required to move to Abbassia, Egypt, outside of Cairo, where Appleby's officers remarked, "Eastern and Western customs meet, and ancient and modern types of people and practice are set in contrast." ${ }^{16}$ Clearly keen to the historical significance of the area, the facility opened in late August initially with 400 beds. By 1916, the hospital had grown to over 1,040 beds and convalesced over 10,000 patients. With recognition of the No.7's diligent efforts, the decision was made to move the unit back to the western front, and in April 1916, the hospital was re-established in Havre, France. Appleby trained within the surgical unit, referred to as "the Hut," which became a 40-bed entity complete with X-ray, sterilization equipment, and a "tarpaulin floor and petroleum lighting." 3 By late summer 1916 and "the beds filled to capacity, and summer warmth established," the company noted the "pleasure of work as regards all ranks of personnel" had reached its highest point. ${ }^{16}$

During his years abroad, Appleby received teaching under the direction of various medical officers. ${ }^{16}$ Anatomy, taught by a Major GE Kidd, comprised of daily dissections, lectures, demonstrations, and "grinds." 16 Other coursework including "Mental diseases by Dr. Warnock" were incorporated into the curriculum and focused on pellagra and "Oriental drug habits." 3 Basic studies including French and Mathematics were also guaranteed for the "knowledgeseeking youths, (who were) note-booked and full 


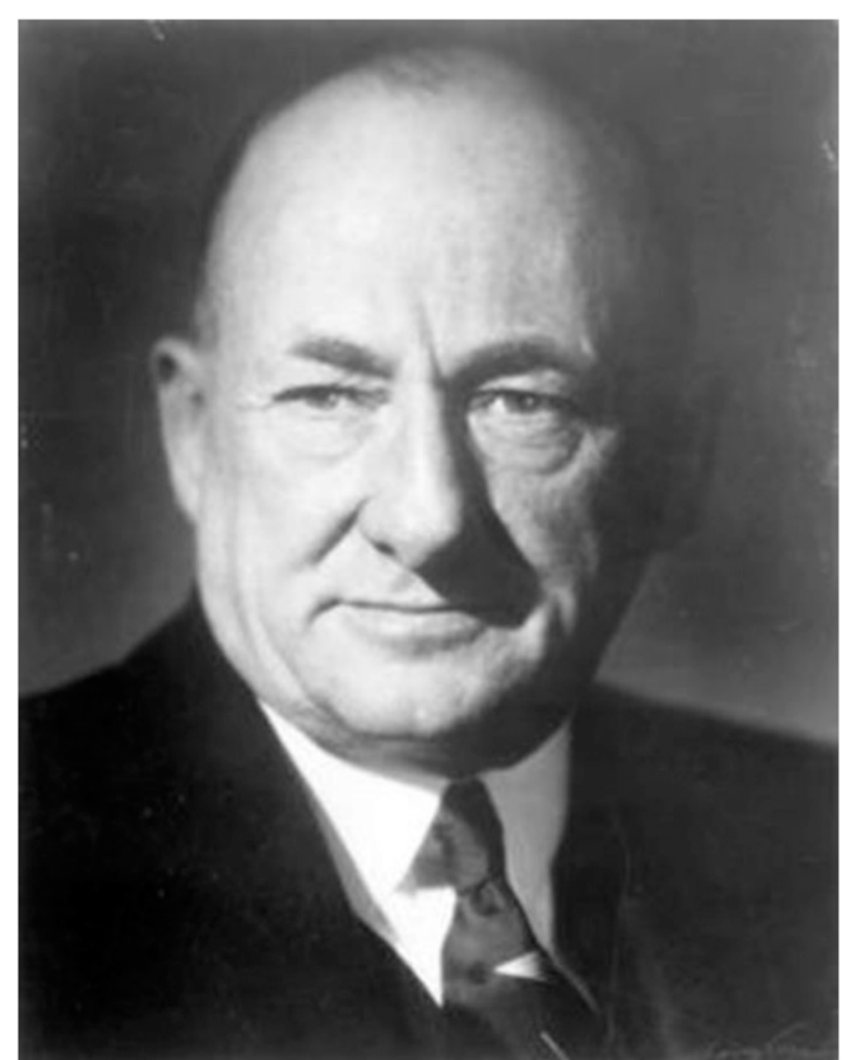

FIG. 1. LH Appleby portrait circa 1955. City of Vancouver Archives. Image retrieved from www.searcharchives.vancouver.ca. Accessed August 8, 2015.

of college songs." 3 Complimenting his academic endeavors, Appleby maintained physical health by playing shortstop for the Canadian baseball team. After three years of service, Appleby returned to Canada to complete his degree. At Queen's he was awarded with the Gold Medal, a distinction given to the highest achieving member of his or her field of study in $1919 .{ }^{1}$ Appleby returned to a postwar Europe to finalize his medical training, and in 1921, he came home to Canada to begin practicing. He was the 13th Canadian and youngest recipient of his fellowship title in the British Empire. ${ }^{1}$

It is unclear as to his reasoning for heading Westward in 1927 to practice at St. Paul's Hospital in Vancouver, Canada, but Appleby did so after being hired at the 30-year-old institution. Perhaps related to his journeyman and self-made ways, Appleby settled in Vancouver, originally a territorial inlet that thrived off of the lumber industry. ${ }^{4}$ Medical practitioners, many from McGill in Montreal, became permanent residents of Vancouver and soon after arriving, began forming general practitioner collectives for the inhabitants. In 1894, the first iteration of St. Paul's was founded. Known as the Sisters of Providence, the 25-bed unit became a common facility shared by the local physicians. ${ }^{4}$ In 1919, however, the American College of Surgeons (ACS) began a process of standardization in hospitals across North America which St. Paul's readily endorsed. The resulting Medical Advisory Board of St. Paul's strove to maintain the high standard dictated by the ACS and did so as the faculty reached "full maturity" about 20 years postinduction of the various protocols. ${ }^{4}$ In 1927, Appleby was hired to the surgical staff, and true to his military background, imparted his standard of excellence on the department. He chaired various committees including the "Committee to Interview with Mother Superior," the matriarch of the Catholic underpinning of the hospital. ${ }^{4}$ In this role, Appleby compiled statistical data collected by the department with particular emphasis on typhoid, a reminder of his time spent on the frontline. Other committee roles lead by Appleby included the Intern Selection Committee, which strove to attract highminded and character individuals to the burgeoning institution. In cosmopolitan fashion, Appleby recruited a long-time friend's son after he had left to practice in Rome, a testament to the international influence of Appleby on the surgical landscape of the mid-20th century. More perfunctory tasks such as emergency department inflow and outflow, billing dilemmas, and data collection with specific reports on cancer, head injuries, and intestinal obstruction, continued to be areas Appleby remained fastidious about and handled deftly. ${ }^{4}$ In terms of policy, Appleby advocated for full licensure of physicians practicing both medicine and dentistry in British Columbia, and internally, he decreed that "a $60 \%$ attendance rate at all staff functions must be maintained and roll signed." 4 Clearly, the character of St. Paul's became one of order and excellence with the leadership provided by Dr. Appleby. His merit was awarded with appointment as Chairman in 1941, and he served until $1943 .{ }^{4}$ With a growing reputation surgically and academically, Appleby was elected as president of the International College of Surgeons in 1962 and held his term through 1964. ${ }^{1}$ A truly global surgeon, Appleby continued to campaign against complacency and stagnant standards of care. He envisioned an era of surgical advancement that evolved into the modern model of surgical training. On a local level, he remained on faculty at St. Paul's until 1968, receiving a multitude of awards including the "PIP award" in 1960 for his outstanding service to the Vancouver Medical Community. ${ }^{3}$ Additional national roles included being elected Fellow at the Royal College of Physicians and Surgeons of Canada in Ontario. ${ }^{1}$

A consummate academic surgeon, Appleby, published prolifically on the advancement of surgical technique. Within general surgery, he published on rectal, breast, and gastric carcinomas with 
considerable frequency. ${ }^{5-9}$ Other interests included anomalous physical exam and anatomical findings, one of which included "nonmalignant intrinsic stricture of the pancreatic duct." ${ }^{5-9}$ Additional areas of investigation included anesthesia techniques, vagotomy, and "autotrasnsfusion." -9 Perhaps his most enduring work, and the impetus for this paper, is the "Appleby procedure," a radical resection of the celiac axis for local control and extended lymphadenectomy and originally intended for invasive gastric cancers. This procedure has since been modified and now used in selected pancreas cancer operations. Appleby's seminal manuscript, "The Coeliac Axis in the Expansion of the Operation for Gastric Carcinoma," presented to the American Cancer Society in 1952 and published in 1953, demonstrates Appleby's surgical audacity and devotion to technical advancement. ${ }^{2}$ Describing the management of gastric cancer as "wholly inadequate," he proposed expansion of the procedure to thoroughly harvest nodes, which had been previously "picked out piecemeal like currants out of a bun." ${ }^{2} \mathrm{He}$ astutely commented that in all recurrences of gastric cancer, lymphatics were involved and "removal of the drainage areas of the stomach must be ensured."2 Furthermore, Appleby proposed that hepatic arterial flow can be maintained through an arcade between the gastroduodenal artery and the inferior pancreaticoduodenal branch of the superior mesenteric artery in addition to "aberrant hepatic arteries from the aorta or superior mesenteric chains." ${ }^{2}$ Expanding the work of his colleagues, he boldly surmised, "ligature of the main hepatic artery proximal to the gastroduodenal junction can be done with impunity," a testament to his will to investigate treatment beyond the standards of care. Interestingly, he believed that the role of arterial flow to the liver was to "prevent the development of anaerobic organisms in the liver," a notion that could be trumped with liberal usage of antibiotic. ${ }^{2}$ The first patient of 13 patients to have an "Appleby procedure" performed was a 63-year old whose "complaints were indigestion, some weight loss, and a sense of fatigue." He successfully underwent the procedure in 1949. Of the successful operation Appleby wrote, "I cannot help but believe that the primary assault on any cancer is the moment of golden opportunity and that any risk is justifiable in the face of the awful alternative," ${ }^{2}$ his overall results with celiac axis resection-his own total experience, commensurate words on the role he held as clinician and healer.

A steward of medical history, Appleby published in 1934, "The Medical Life of Henry the Eighth," a 16-page treatise on the nexus between medicine, nobility, and political change. ${ }^{10}$ Demystifying the reign of Britain's ruthless sovereign, Appleby succinctly defines the trajectory of the Tudor dynasty by the introduction of the "scarlet thread of syphilis." 10 Appleby writes how Henry's life and "insanity," a result of his early exposure to the disease, was compounded by this concupiscent behavior. As the disease ravaged his mind, his licentious proclivities abounded, and "dynastic urge" ultimately lead to the severing of England from the Roman Catholic Church. ${ }^{10}$ Furthermore, apparent Oedipal overtones defined Henry's rule, and his ultimate passing from heart failure and cirrhotic disease portray the gluttonous entreaties of a bombastic King. Appleby poses the query "guilty of infamous cruelty, or not?" and he concludes "guilty, but irresponsible, due to the ravages of untreated lues," 10 tactfully summarizing the impact of health on the course of history.

In his free time, Appleby's competitive spirit and penchant for equestrian sport became renowned (Fig. 2). Winning the Durham Stakes in 1944 with his horse "Maginot Line" solidified his pre-eminence in the sport, and an additional victory in the Cup and Saucer Stakes in Toronto in 1947 with the horse "Ohsodry" extended his pre-eminence to the track. ${ }^{11,12}$ As in the hospital, Appleby's iconoclastic ways marked history in horse racing; he raced the first Western-Canadian born horse "Cum Laude" in the coveted Queen's Plate in 1944 and finished fifth after an "arduous journey by

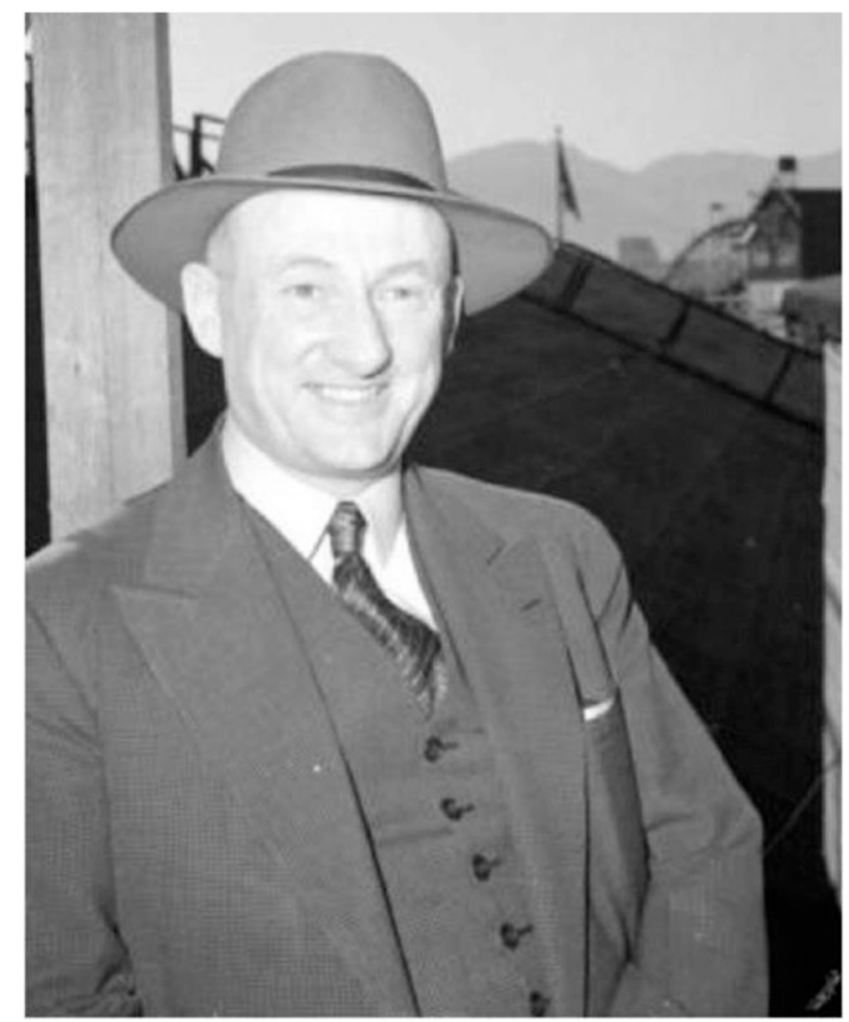

FIG. 2. LH Appleby at Hastings Park Race Track in Vancouver circa 1942. City of Vancouver Archives. Image retrieved from www.searcharchives.vancouver.ca. Accessed August 8, 2015. 
rail." 13 His achievements on the race grounds earned him entrance into the Canadian Racing Hall of Fame and a legacy remembered by with the Appleby Award, which is presented to a horse yearly bred in British Columbia. ${ }^{14}$

Dr. Appleby passed from natural causes in 1970 at the age of 75 years. Marked by continual excellence, his legacy both professionally and personally, will long be remembered. He is quoted as saying "it is much easier to stay out of trouble than it is to get out of trouble," 15 wisdom that surgeons both young and venerated should heed as they attempt to emulate his life and work.

\section{REFERENCES}

1. Appleby, Henry Lyon. (1895-1970). Plarr's Lives of the Fellows Online. Available at: livesonline.rcseng.ac.uk. Accessed August 9, 2015.

2. Appleby LH. The celiac axis in the expansion of the operation for gastric carcinoma. Cancer 1953;6:704-7.

3. Vancouver Medical Association. PIP Awards. Moneo Medical Informatics. Available at: www.vancouvermedicalassociation. ca. Accessed August 22, 2015.

4. Keith WDSt. Paul's Hospital Vancouver, B.C.: The History of the Medical Staff 1920-1940. Providence Health Care. Available at: www.chac.ca. Accessed August 9, 2015.
5. Appleby LH. Discussion on the treatment of advanced cancer of the rectum. Proc R Soc Med 1950;43:1071-81.

6. Appleby LH. An unusual arrangement of the external genitalia. Can Med Assoc J 1923;13:514-5.

7. Appleby LH. Nonmalignant intrinsic stricture of the pancreatic duct. Report of a case. Arch Surg 1951;63:115-8.

8. Appleby LH. An assessment of the results of vagotomy based upon personal experience of 66 cases. Can Med Assoc J 1948;59: 58-62.

9. Appleby LH. Autotransfusion. Can Med Assoc J 1925;15:36-7. 10. Appleby LH. The Medical Life of Henry the Eighth. Vancouver: The Vancouver Medical Association Bulletin, 1934.

11. Thoroughbred Database. Durham Stakes Pedigree Online. Available at: www.pedigreequery.com. Accessed August 22, 2015.

12. Thoroughbred Database. The Cup and Saucer Pedigree Online. Available at: www.pedigreequery.com. Accessed August 22, 2015.

13. Cauz L. (2009). Even world war couldn't bring Plate to a halt. The Toronto Star. Available at: www.thestar.com/sports. Accessed August 22, 2015.

14. Goulding R. (2011). 2011 Hall of Fame: Awards and Honours. The Canadian Racing Hall of Fame. Available at: www.cthsbc.org. Accessed August 9, 2015.

15. Maher L. Memories of a Cariboo Doctor. Bloomington: Trafford Publishing, 2006.

16. A History of No. 7 (Queen's) Canadian General Hospital. Ontario: C.W. Faulkner \& Co, Ltd, 1917. 